\title{
Supporting teachers in their use of ICT in teaching mathematics: what kind of support is necessary and when is it required?
}

\begin{abstract}
This article reports on a study that was carried out to establish determinants of ICT integration in mathematics teaching and learning. This paper focuses on the kind of support teachers require to effectively use ICT in teaching mathematics. An exploratory sequential mixed methods research design was employed to conduct this study in which quantitative data was initially collected in the first phase. Qualitative data was then collected in the second phase to explain the quantitative data collected in the initial phase. The study targeted all the teachers teaching in lower grades in both private and public schools. A sample size of 40 lower primary schools were purposively selected based on the availability of ICT tools for instructional purposes in those schools. Three teachers teaching in grade one, two and three were then selected using simple random sampling technique especially in cases where more than three teachers existed. Teacher Questionnaire, Teacher Interview Protocol and Observation Protocol were used to collect data. Data was analyzed qualitatively using descriptive phenomenological analysis in which data transcriptions were divided into themes and sub-themes related to phenomena under study. The findings of the study revealed that there was a significant relationship between supporting teachers' use of ICT in the classroom and their actual use of ICT in teaching mathematics. The study findings however revealed that teachers teaching lower grades in Mombasa, Kenya were not adequately supported in their use of ICT in teaching mathematics. It was recommended that teachers must be granted adequate support in their use of ICT in teaching mathematics.
\end{abstract}

Keywords: Information and communication technology, mathematics teaching, mathematical learning, technical support, support in professional development, integration programme, development programme, technician, standby technician, technical support
Special Issue - 2018

\author{
Benard Ashiono, Catherine Gakii Murungi, \\ Teresa Mwoma \\ Department of Early Childhood Studies, Kenyatta University, \\ Kenya
}

Correspondence: Catherine Gakii Murungi, Department of Early Childhood Studies, Kenyatta University, PO-43844-00100, Nairobi, Kenya, Email Catherine_gakii@yahoo.com

Received: July 12, 2018 | Published: December 31, 2018

\section{Introduction}

The use of ICT in delivery of school curriculum in the developing world, Kenya included is still insignificant. According to Ashiono Teresa and Catherine, ${ }^{1}$ majority of teachers do not possess adequate expertise required to use ICT for teaching mathematics. Tondeur $\mathrm{J}^{2}$ emphasized the importance of supporting teachers in the course of improving their expertise in teaching with ICT. They further argued that this kind of support should go beyond the mere organization of training sessions for teachers to improve their technical competencies. Likewise, Ashiono Teresa and Catherine, ${ }^{1}$ argued that the pedagogical challenge of using ICT in teaching calls for teachers not only to acquire ICT skills but also to understand most importantly the methods of teaching using ICT to enhance learning. Therefore professional development of teachers as well as technical support in the use of ICT in teaching is key in the implementation of ICT integration programme in the classroom.

\section{Technical support}

Inan and Lowther ${ }^{3}$ in their study in USA examined the effects of teachers' characteristics and factors that influence their use of ICT in teaching. The findings of the study found that technical support had a significant influence on teachers' beliefs about the importance of ICT in teaching. The study findings also revealed that teachers' beliefs significantly influenced their subsequent use of ICT in teaching. In his extensive literature review on contextual factors influencing uptake of ICT use in classroom, Murungi and Gitonga ${ }^{4}$ found that technical support to teachers in use of ICT was amongst key factors. Jones ${ }^{5}$ observed that lack of technical support to teachers in their use of ICT in teaching leads learning interruptions as a result of breakdown of ICT tools. Therefore it is imperative that teachers are accorded the requisite technical support in their use of ICT in delivery of school curriculum Murungi and Gitonga. ${ }^{4}$ BECTA $^{6}$ indicated that there was a general lack of technical support in British schools which consequently resulted in frustrations and apathy among teachers in the use of ICT in teaching. Furthermore, Tong and Trinidad noted that lack of technical support frustrated teachers resulting in their unwillingness to use ICT in teaching.

\section{A. Teacher Professional development in ICT use in teaching}

Ashiono, et al. ${ }^{1}$ observed that teachers' confidence and competency in selecting and using ICT in the classroom largely depends on their training and professional development in ICT use. Murungi and Gitonga, ${ }^{4}$ extensively reviewed literature on factors influencing teachers' adoption and use of ICT in teaching. He found that one of the key factors influencing teachers' adoption of ICT in teaching was school leadership support in teacher professional development. Tondeur ${ }^{5}$ in their study in Kenyan secondary schools on use of ICT in teaching found that ICT use by students in the classroom was insignificant. The findings of this study revealed that teachers 
were unable to use ICT for pedagogy before the start of a teacher Professional Development (PD) programme, which was embedded in the study. The findings of the study further revealed that the teachers began to significantly use ICT in teaching at the end of the two-year teacher professional development programme. The results of this study implied that teachers' lack of expertise in the use of ICT in teaching as one of the major challenges hindering effective integration of ICT in the classroom practice. Therefore, Mingaine ${ }^{7}$ argues that teacher professional development is of paramount importance to the successful implementation of ICT integration programme in educational settings.

Cubukcuoglu ${ }^{8}$ study in Northern Cyprus examined factors enabling use of ICT in secondary schools. The study employed the use of semi-structured interviews to collect data from teachers. The findings of the study revealed that there was lack of adequate training among teachers in pedagogical use of ICT in teaching. The teachers noted that adequate training of teachers was an important enabler in the use of ICT in classroom instruction. The teachers viewed sufficient training as a necessity in the effective use ICT in teaching.

\section{Results and discussion}

In this study, teachers were asked to respond to four items of the teacher questionnaire on management and support in the use of ICT in teaching mathematics. They were asked to indicate whether there was: a technician in the school; whether there was adequate technical support in the use of ICT in teaching; whether there was adequate maintenance of ICT facilities and finally whether there were adequate opportunities for professional development in the use of ICT in teaching mathematics. The teachers responded by ticking one of the following alternatives provided: Clearly no, Mostly no, Not sure, Mostly yes, and clearly yes. The results of the study are shown below (Table 1).

The findings of the study as shown on Table 1 indicate that majority of the schools did not have a standby technician. Only a fifth $(20 \%)$ of the teachers indicated that there was a technician in the school. The study also found that approximately a third (37\%) of the teachers received technical assistance from their respective schools in the use of ICT in teaching mathematics. Also about a third (37\%) of the teachers indicated that there was regular maintenance of the ICT tools. Finally, the study found that only a quarter of the teachers received support from their school in their course of professional development. Three quarters of the teachers did not get any support from their schools in their quest for professional development in the integration of ICT into their classroom practice.

\section{A. The relationship between support and teachers' use of ICT in teaching mathematics}

To explore whether there is a relationship between technical and teacher professional development (PD) support and teachers actual use of ICT in teaching mathematics; the following hypothesis was tested using One Way ANOVA at .05 sig level. $\mathrm{H}_{3} 0$ : There is no significant difference in the use of ICT devices in teaching mathematics between teachers who receive support and those who do not.

\section{Technical support}

To explore this relationship, the researcher gathered data from teachers on whether they received technical support in their use of ICT tools in teaching mathematics. Teachers were asked to respond to the following item of the TQ: There is adequate technical support for use of ICT in teaching and learning mathematics. They responded by ticking one of the following alternatives: Clearly $\mathrm{No}_{0}=1$, Mostly $\mathrm{No}=2$, Not Sure $=3$, Mostly Yes $=4$, and Clearly Yes $=5$. One way ANOVA between groups was conducted to explore the influence of technical support to teachers (as measured by technical support scale on the TQ) on their use of ICT in teaching mathematics (as was measured by a score on TQ on teachers' use of ICT in teaching mathematics). Subjects were divided into two groups: those who received technical support in use of ICT in teaching mathematics and those who did not receive that kind of support. The results of the ANOVA test are presented below (Table 2).

Table 2 indicates that the calculated value $\mathrm{p}=0.003<0.05$ with a calculated $\mathrm{F}=4.22$ at $4 \mathrm{df}$ (degrees of freedom). This result shows that the $p$ value of 0.003 was less than the critical value of 0.05 . Therefore the difference in means was found to be significant and the null hypothesis was thus rejected. This finding implies that there was a significant difference in means in the use of ICT in teaching mathematics between teachers who received technical support and those who did not. This finding therefore suggested that technical support to teachers significantly influence their use of ICT in teaching mathematics. To determine the effect size of technical assistance on use of ICT in teaching mathematics, eta squared was computed. Eta squared is calculated by dividing the sum of squares for between groups by the total sum of squares in the ANOVA table. Table 3 indicates that sum of squares between groups is 37.262 and total sum of squares is 266.606; which resulted in 0.1398. This can be rounded off to .14. According to Cohen and Manion ${ }^{9}$ classification of effect size, .14 would be considered a large effect size. This could be interpreted to mean that $14 \%$ of variance in use of ICT in teaching mathematics could be attributed to technical assistance teachers received in their use of ICT tools in their teaching. Post-hoc multiple comparisons using Tukey HSD test was performed to establish which groups of teachers were significantly different in their use of ICT in teaching mathematics. The results of the Post-hoc analysis test are presented below (Table 3).

The results of the Post-hoc analysis as shown on Table 3 reveal that groups of teachers who indicated 'Clearly No', Not Sure' and 'Clearly Yes' differed significantly from each other in terms of their use of ICT in teaching mathematics. The result suggests that the group of teachers who indicated that they received technical support (Clearly Yes groups) differed significantly in their use of ICT in teaching mathematics with groups of teachers who did not receive technical support (Clearly No and Not Sure groups). This finding implies that advancing technical assistance to teachers significantly influences their use of ICT in teaching mathematics. This finding is consistent with findings from a previous study by Wanjala which found that there was a significant relationship between technical support and teachers' use of computers in teaching mathematics. The findings from Wanjala study revealed that most teachers do not possess sufficient expertise in computer use for instructional purposes. Tong and Triniada argue that lack of technical support for teachers make them to become frustrated with ICT tools consequently resulting in their reluctance in use of ICT in their teaching. Becta ${ }^{6}$ argue that lack of technical support may result in lack of technical maintenance of ICT tools resulting in higher risks of technical failure of ICT tools during teaching and learning process. Therefore, Yilmaz asserts that besides equipping schools with ICT hardware, software and internet, it is necessary to provide teachers with technical support in the use of these tools in teaching. ${ }^{10,11}$ 


\section{Supporting teachers in the course of their professional development}

To explore this relationship, the researcher collected data from teachers on whether they received support in their professional development in the use of ICT tools in teaching. They were asked to respond on the following item of the TQ: There are adequate opportunities for professional support in the use of ICT in teaching. They responded by ticking one of the following alternatives: Clearly $\mathrm{No}=1$, Mostly $\mathrm{No}=2$, Not Sure $=3$, Mostly Yes $=4$, and Clearly Yes=5. Likewise, One way ANOVA between groups was conducted to explore the influence of the support teachers received in the course of their professional development (as measured by a scale on support to teachers' professional development on the TQ) on their use of ICT in teaching mathematics (as was measured by a score on TQ on teachers' use of ICT in teaching mathematics scale). Subjects were divided into two groups: those who received support in the course of their professional development in using ICT in teaching and those who did not receive that kind of support. The results of the ANOVA test are presented on Table 3.

Table 4 indicates that the calculated value was $p=0.00<0.05$ with a calculated $\mathrm{F}=36.45$ at $4 \mathrm{df}$ (degrees of freedom). This results shows that $p$ value of 0.00 is less than the critical value of 0.05 . The result also shows that the F statistic (36.4) is substantial, meaning there is more variance between and within groups. The difference in means for the three groups of teachers who received support in their PD (Clearly Yes) and those who did not receive support in their PD (Clearly No and Not Sure groups) were found to be significant. The null hypothesis was therefore rejected on the basis of this result (Table 4).

To determine the effect size of supporting teachers' professional development on their use of ICT in teaching mathematics, eta squared was computed. Table 3 shows that the sum of squares between groups was 131.561 and the total sum of squares was 225.413. Therefore, eta squared computed was 0.58 . According to Cohen (1988) .58 would be considered a large effect size. This result could be interpreted to mean that nearly $58 \%$ of the variance in the use of ICT in teaching mathematics could be attributable to the support teachers receive in pursuing professional development course in the use of ICT for pedagogical purposes. Post-Hoc multiple comparisons using Tukey HSD test was performed to establish the groups of teachers which significantly differed in their use of ICT in teaching mathematics. The results of the Tukey HSD test are presented below (Table 5).

The results of the Tukey HSD Test as shown on Table 5 reveal (as indicated with the asterisk *) that all the groups of teachers significantly differed in their own use of ICT in teaching mathematics. The result indicates that groups of teachers who indicated 'Clearly No' and Not Sure' differed significantly with the group that indicated 'Clearly Yes' in their use of ICT in teaching mathematics. Therefore, teachers who were supported in their course of professional development in ICT differed significantly in the use of ICT in teaching mathematics with the groups of teachers not supported. This finding implies that supporting teachers in pursuing their professional development course in ICT significantly influences their use of ICT in teaching mathematics. This finding is consistent with findings from Murungi and Gitonga ${ }^{4}$ study that found that teachers' professional development is a vital ingredient in the successful use of ICT in classroom instruction. This study revealed that teachers' ICT-related training programmes developed and increased teachers' competencies in ICT use in class. Likewise, professional development courses in ICT influences teachers' attitudes towards use of ICT in teaching. It is therefore of great essence to support teachers in their pursuance of professional development courses in ICT use in teaching mathematics.

Table 1 Descriptive statistics on support teachers receive in the use of ICT to teach mathematics

\begin{tabular}{llllll}
\hline Statement & Clearly No & Mostly No & Not Sure & Mostly Yes & Clearly Yes \\
\hline There is a technician in the school & $486.80 \%$ & $19.30 \%$ & $13.80 \%$ & $12.80 \%$ & $7.30 \%$ \\
There is technical support in using ICT & $44.00 \%$ & $4.60 \%$ & $14.70 \%$ & $21.10 \%$ & $15.60 \%$ \\
There is regular maintenance of ICTs & $39.40 \%$ & $4.60 \%$ & $18.30 \%$ & $19.30 \%$ & $18.30 \%$ \\
There is adequate support for training & $59.60 \%$ & $6.40 \%$ & $8.30 \%$ & $18.30 \%$ & $7.30 \%$ \\
\hline
\end{tabular}

Table 2 ANOVA Computations on Differences in Use of ICT between Teachers with and Without Support

\begin{tabular}{llllll}
\hline & Sum of Squares & df & Mean Square & F & Sig. \\
\hline Between Groups & 37.262 & 4 & 9.315 & 4.224 & 0.003 \\
Within Groups & 229.344 & 104 & 2.205 & & \\
Total & 266.606 & 108 & & & \\
\hline
\end{tabular}

*The mean differences are significant at the 0.05 level 
Table 3 Post hoc comparisons on teachers with and without technical support in the use of ICT Using Tukey HSD Test

\begin{tabular}{lllllll}
\hline $\begin{array}{l}\text { (I) There is adequate } \\
\text { technical support }\end{array}$ & $\begin{array}{l}\text { (J) There is adequate } \\
\text { technical support }\end{array}$ & $\begin{array}{l}\text { Mean } \\
\text { Difference (I-J) }\end{array}$ & Std. Error & Sig. & 95\% Confidence Interval \\
& & & & & Lower Bound & Upper Bound \\
\hline Clearly No & Not Sure & 0.458 & 0.429 & 0.822 & -0.73 & 1.65 \\
& Clearly Yes & $-1.365^{*}$ & 0.419 & 0.013 & -2.53 & -0.2 \\
Not Sure & Clearly No & -0.458 & 0.429 & 0.822 & -1.65 & 0.73 \\
& Clearly Yes & $-1.824^{*}$ & 0.517 & 0.006 & -3.26 & -0.39 \\
Clearly Yes & Clearly No & $1.365^{*}$ & 0.419 & 0.013 & 0.2 & 2.53 \\
& Not Sure & $1.824^{*}$ & 0.517 & 0.006 & 0.39 & 3.26 \\
\hline
\end{tabular}

*.The mean difference is significant at the 0.05 level.

Table 4 ANOVA Computations on differences in use of ICT between teachers with and without support in their PD

\begin{tabular}{llllll}
\hline & Sum of Squares & df & Mean Square & F & Sig. \\
\hline Between Groups & 131.561 & 4 & 32.89 & 36.446 & 0 \\
Within Groups & 93.852 & 104 & 0.902 & & \\
Total & 225.413 & 108 & & &
\end{tabular}

*The mean differences are significant at the 0.05 level

Table 5 Post hoc comparisons on groups of teachers with and without PD support in the use of ICT in teaching mathematics using Tukey HSD Test

\begin{tabular}{|c|c|c|c|c|c|c|}
\hline \multirow[t]{2}{*}{$\begin{array}{l}\text { (I) There is adequate } \\
\text { technical support }\end{array}$} & \multirow[t]{2}{*}{$\begin{array}{l}(\mathrm{J}) \text { There is adequate } \\
\text { technical support }\end{array}$} & \multirow[t]{2}{*}{$\begin{array}{l}\text { Mean Difference } \\
\text { (I-J) }\end{array}$} & \multirow[t]{2}{*}{$\begin{array}{l}\text { Std. } \\
\text { Error }\end{array}$} & \multirow[t]{2}{*}{ Sig. } & \multicolumn{2}{|c|}{ 95\% Confidence Interval } \\
\hline & & & & & Lower Bound & Upper Bound \\
\hline \multirow[t]{2}{*}{ Clearly No } & Not sure & -0.688 & 0.274 & 0.097 & -1.45 & 0.07 \\
\hline & Clearly yes & $-3.158 *$ & 0.268 & 0 & -3.9 & -2.41 \\
\hline \multirow[t]{2}{*}{ Not Sure } & Clearly no & 0.688 & 0.274 & 0.097 & -0.07 & 1.45 \\
\hline & Clearly yes & $-2.471 *$ & 0.331 & 0 & -3.39 & -1.55 \\
\hline \multirow[t]{2}{*}{ Clearly Yes } & Clearly no & $3.158^{*}$ & 0.268 & 0 & 2.41 & 3.9 \\
\hline & Not sure & $2.471^{*}$ & 0.331 & 0 & 1.55 & 3.39 \\
\hline
\end{tabular}

*.The mean difference is significant at the 0.05 level.

\section{Conclusion}

The sought to determine the kind of support teachers received in their use of ICT in teaching mathematics. The study found that there was inadequate support to teachers in the use of ICT in teaching mathematics. The findings of the study indicated that most of the lower primary schools in Mombasa County did not have a standby technician to give teachers technical support in their use of ICT in teaching. Only $20 \%$ of the teachers indicated that there schools had a standby technician in the school. The study also found that only $37 \%$ of the teachers received technical support in their use of ICT in teaching mathematics. Further, the study findings revealed that majority of the teachers did not receive support in pursuing professional development courses in their use of ICT in teaching mathematics. The study found that three quarters $(74 \%)$ of the teachers did not receive any form of support from their schools in pursuit of professional development courses on the use of ICT in teaching. Only a quarter of teachers indicated that they were supported by their head teachers in pursuing professional development courses relation to the use of ICT in teaching mathematics.

The study further explored the relationship between teachers' technical and professional development support and their use of ICT in teaching mathematics. This relationship was explored using One Way ANOVA technique at $0.05 \mathrm{sig}$ level. The study found a significant difference in the use of ICT in teaching mathematics between teachers who received technical support and those who did not receive support. Furthermore, the study found a significant difference between teachers who received support in their course of professional development and those who did not receive that kind of support. This finding implies that providing teachers with technical support as well as supporting 
their professional development course positively influenced them to use ICT in teaching mathematics.

\section{Acknowledgments}

None.

\section{Conflicts of interests}

Author declares that there is no conflict of interests.

\section{References}

1. Ashiono B, Mwoma T, Murungi CG. Does the use of ICT empower teachers to teach Mathematics better? A case of lower primary teachers in Mombasa. Matters of Behaviour. 2018;2(1):10-20.

2. Tondeur J, Krug D, Bill $\mathrm{M}$, et al. Integrating ICT in Kenyan Secondary Schools: An exploratory case study of a professional development programme. Technology, Pedagogy and Education. 2015;24(5);565-584.

3. Inan FA, Lowther DL. Factors affecting technology integration in K-12 classrooms: a path model. Education Tech Research Dev. 2010;58(2):137-154

4. Murungi CG, Gitonga R. Active Learning with Technology Tools in the Blended/Hybrid Classes. Book chapter published in the book "Handbook of Research on Educational Technology Integration and Active Learning. 2015.

5. Jones A. A Review of the Research Literature on Barriers to the Uptake of ICT by Teachers. British Educational Communications and Technology Agency.2004.

6. BECTA. A review of the research literature on barriers to the uptake of ICT by teachers. 2004

7. Mingaine L. Skill challenges in adoption and use of ICT in public secondary schools, Kenya. International Journal of Humanities and social science. 2013;3(13):61-72.

8. Cubukcuoglu B. Factors enabling the use of technology in subject teaching. International Journal of Education and Development Using ICT. 2013;9(3):50-60.

9. Cohen L, Manion L. Research methods in education (4th Ed.). London: Routledge. 1998.

10. Murungi CG, Gitonga R. Web 2.0 Technologies Use by Students in Higher. 2014

11. Education: A Case of Kenyan Universities. Book Chapter published in the book "Advancing Higher Education with Mobile Learning Technologies: Cases, Trends, and Inquiry-Based Methods" 